\section{Familial Mediterranean Fever in Ashkenazi Jews}

To the Editor:

I have some concerns about the recent article devoted to familial Mediterranean fever (FMF) in Ashkenazi Jews ${ }^{1}$. I think the study is hampered by a lack of definition to determine who actually is an Ashkenazi Jew (as I am myself). The origin that defines Ashkenazi and Sephardic Jews is only a geographic definition, and does not retain any genetic meaning. For example, after 1492, some true Sephardic Jews emigrated to central and oriental Europe.

Conversely, due to events of the 19th and 20th centuries, some Ashkenazi Jews emigrated to North Africa and married there. Such situations did occur frequently in Balkan countries, Bulgaria, and Rumania. If the article was only written to inform the reader that in rare situations, diagnosis of FMF should not be excluded in patients from apparently
Ashkenazi origin, one can accept this. But since the authors draw from their data some clinical, therapeutic, and even genetic considerations, one can regret that the problem of definition has been skipped.

MARCEL-FRANCIS KAHN, MD, Department of Rheumatology, Bichat Hospital, Paris, France. Address correspondence to Dr. Kahn;

E-mail:mfkahn@dbmail.com

\section{REFERENCE}

1. Lidar M, Kedem R, Berkun Y, Langevitz P, Livneh A. Familial Mediterranean fever in Ashkenazi Jews: The mild end of the clinical spectrum. J Rheumatol 2010;37:422-5.

J Rheumatol 2010;37:10; doi:10.3899/jrheum.100485 